NIST Handbook 150-1-2019

\author{
NVLAP \\ Energy Efficient \\ Lighting Products
}

\author{
C. Cameron Miller \\ Timothy Rasinski
}

This publication is available free of charge from:

https://doi.org/10.6028/NIST.HB.150-1-2019

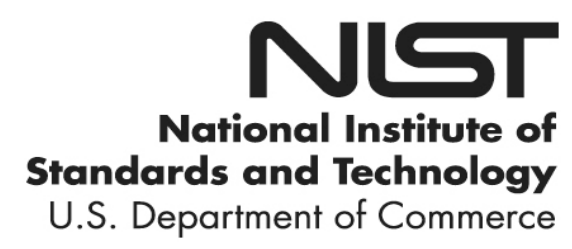


NIST Handbook 150-1-2019

\title{
NVLAP \\ Energy Efficient Lighting Products
}

\author{
C. Cameron Miller \\ Timothy Rasinski \\ National Voluntary Laboratory Accreditation Program \\ Standards Coordination Office \\ Laboratory Programs \\ Dana Leaman \\ Standards Services \\ Standards Coordination Office \\ Laboratory Programs
}

This publication is available free of charge from:

https://doi.org/10.6028/NIST.HB.150-1-2019

February 2019

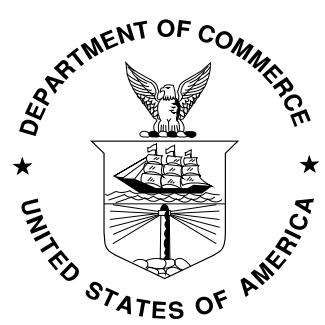

U.S. Department of Commerce Wilbur L. Ross, Jr., Secretary

National Institute of Standards and Technology

Walter Copan, NIST Director and Under Secretary of Commerce for Standards and Technology 


\section{NVLAP AND THE NVLAP LOGO}

The term NVLAP and the NVLAP logo are registered marks of the Federal Government, which retains exclusive rights to control the use thereof. Permission to use the term and symbol (NVLAP logo with approved caption) is granted to NVLAP-accredited laboratories for the limited purpose of announcing their accredited status, and for use on reports that describe only testing and calibration within the scope of accreditation. NVLAP reserves the right to control the quality of the use of the NVLAP term, logo, and symbol. 


\section{Contents}

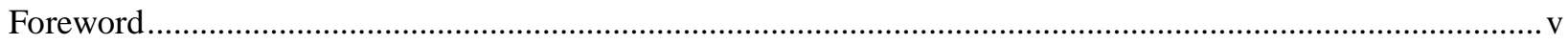

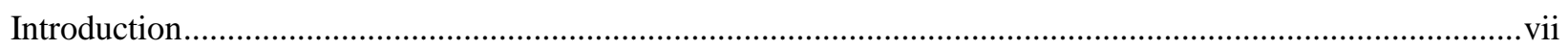

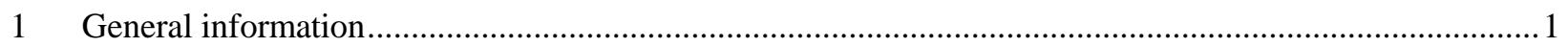

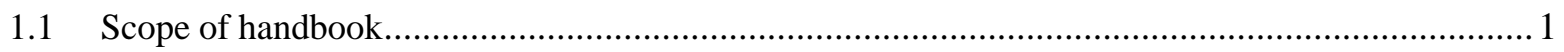

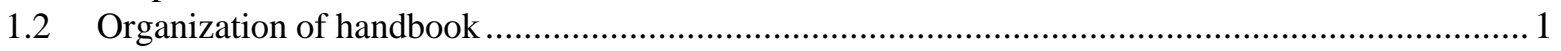

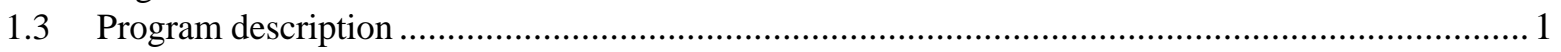

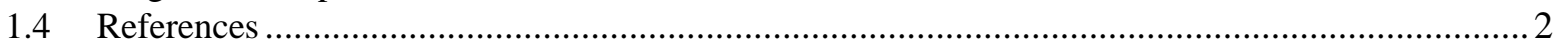

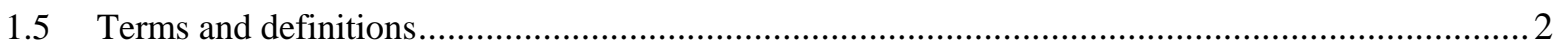

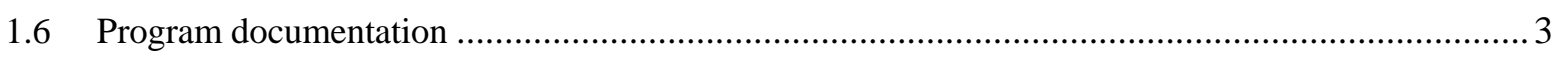

2 LAP establishment, development and implementation ......................................................................

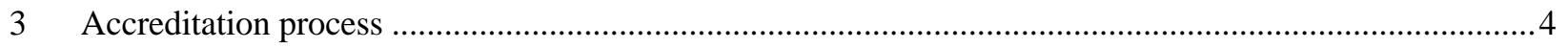

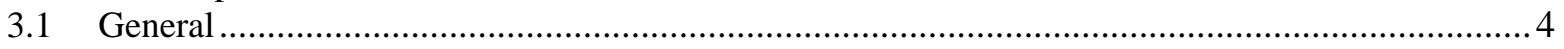

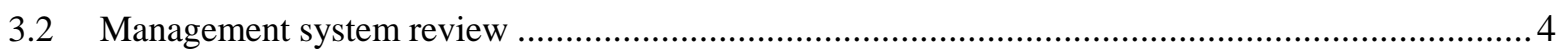

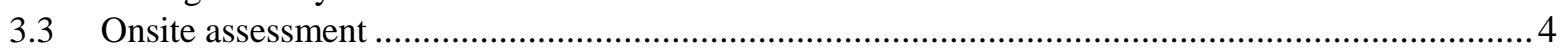

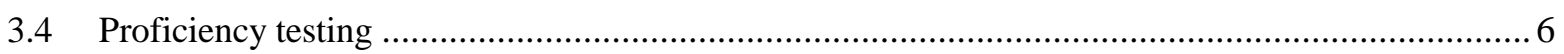

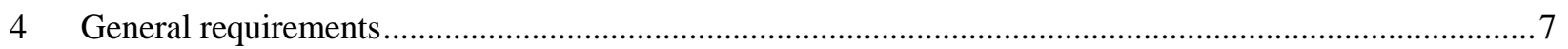

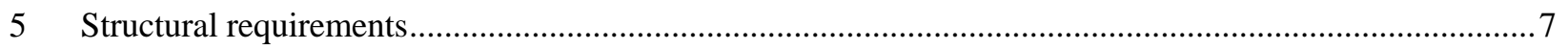

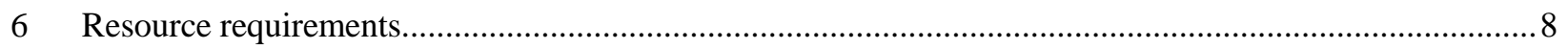

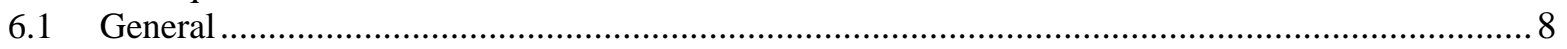

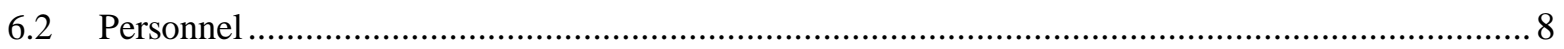

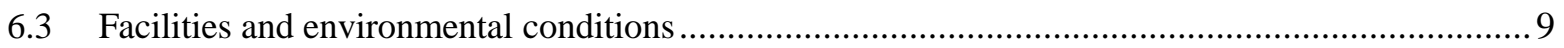

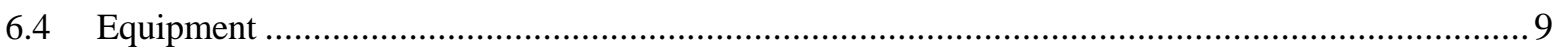

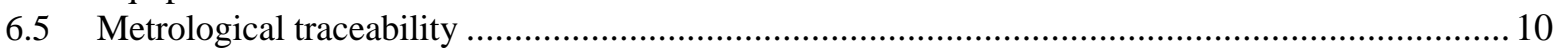

6.6 Externally provided products and services ......................................................................... 10

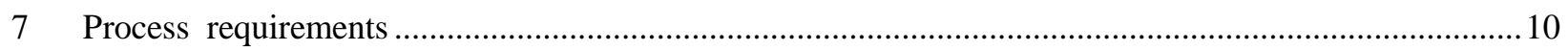

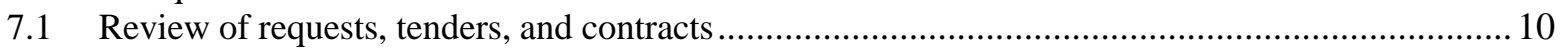

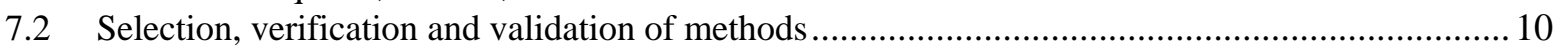

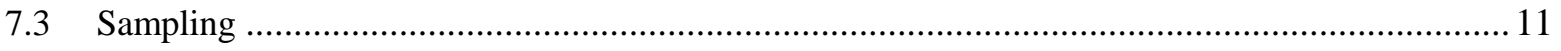

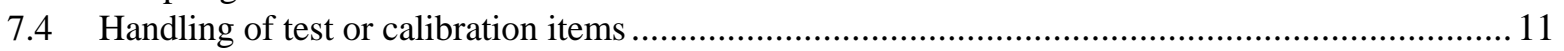

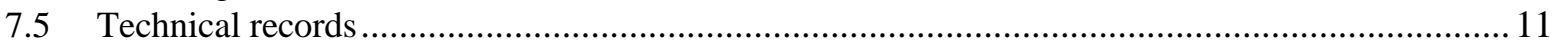

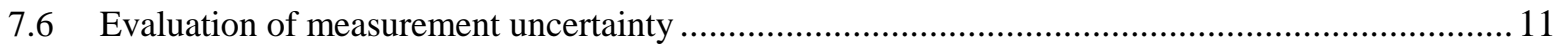

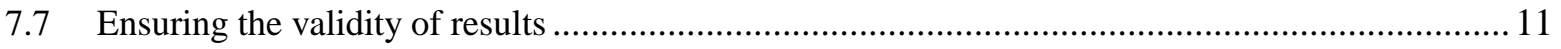

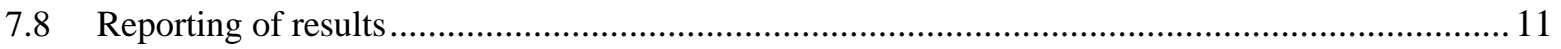

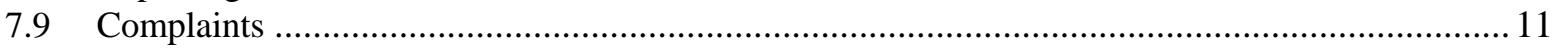

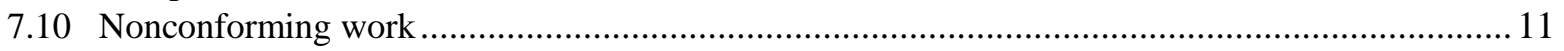

7.11 Control of data and information management ................................................................. 12 


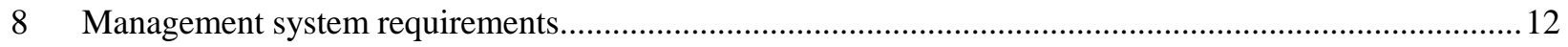

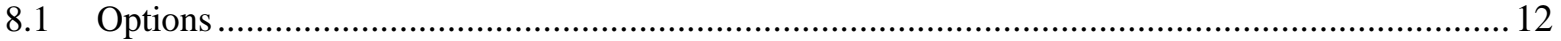

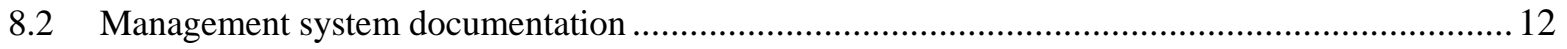

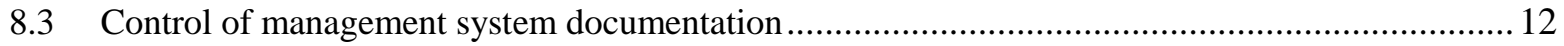

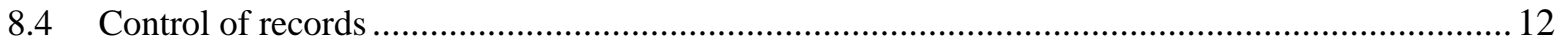

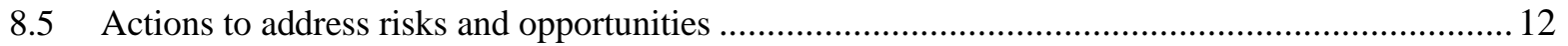

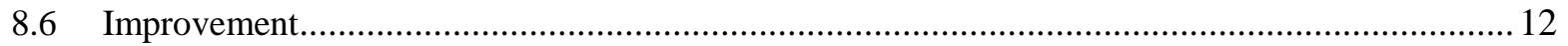

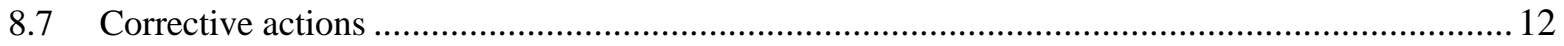

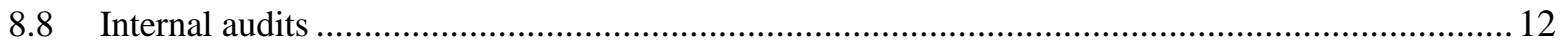

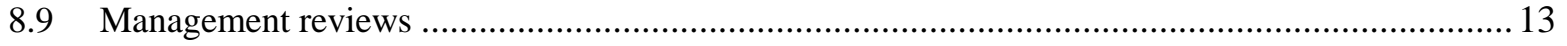

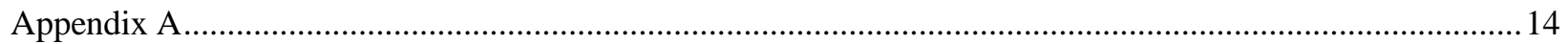




\section{Foreword}

The NIST Handbook 150 publication series sets forth the procedures, requirements, and guidance for the accreditation of testing and calibration laboratories by the National Voluntary Laboratory Accreditation Program (NVLAP). The series is comprised of the following publications:

- $\quad$ NIST Handbook 150, NVLAP Procedures and General Requirements, which contains the general procedures and requirements under which NVLAP operates as an unbiased third-party accreditation body;

- $\quad$ NIST Handbook 150-xx program-specific handbooks, which supplement NIST Handbook 150 by providing additional requirements, guidance, and interpretive information applicable to specific NVLAP laboratory accreditation programs (LAPs).

The program-specific handbooks are not stand-alone documents, but rather are companion documents to NIST Handbook 150 and ISO/IEC 17025:2017. They tailor the general criteria found in NIST Handbook 150 to the specific tests, calibrations, or types of tests or calibrations covered by a LAP.

NIST Handbook 150-1, NVLAP Energy Efficient Lighting Products, presents the technical requirements and guidance for the accreditation of laboratories under the NVLAP Energy Efficient Lighting Products LAP. The 2018 revision aligns this handbook with the 2017 revision of ISO/IEC 17025, General requirements for the competence of testing and calibration laboratories. This handbook is also available on the NVLAP web site (http://www.nist.gov/nvlap).

The assistance of the Energy Efficient Lighting assessors is acknowledged in reviewing this handbook, Mr. Joseph Marella and Ms. Cheryl Levey for editorial review, and Mr. James Leland for providing the table in Appendix A.

Questions or comments concerning this handbook should be submitted to NVLAP, National Institute of Standards and Technology, 100 Bureau Drive, Stop 2140, Gaithersburg, MD, 20899-2140; phone: 301975-4016; fax: 301-926-2884; e-mail: nvlap@nist.gov. 


\section{Introduction}

\section{Background}

As part of broader energy conservation issues, the Energy Policy and Conservation Act (Public Law 94163) was passed in 1975 in response to the oil crisis of the early 1970s. It has been amended several times, most notably in 1992 by the Energy Policy Act (EPAct) (Public Law 102-486). The "Energy Policy Act of 1992" requires that the U.S. Department of Energy specify energy efficiency standards for certain types of fluorescent and incandescent reflector lamps. ${ }^{1}$ New efficiency standards created by the Energy Policy Act of 2005 (EPAct 2005) (Public Law 109-58) were signed into law on August 8, 2005 and went into effect on January 1, 2006.

In the case of luminaires, Public Law 102-486 does not require that the Department of Energy set mandatory energy efficiency standards. Rather, it mandates that the Department of Energy assist industry in developing a voluntary national program that informs consumers of the energy savings to be achieved in selecting certain types of luminaires. Elements of the voluntary program include the selection of the types of luminaires, the specifying of test procedures, and the development of a consumer information system. In this case, the Department of Energy is required to monitor the voluntary program and determine whether it is sufficient to meet the objectives of the Energy Policy Act of 1992.

\section{Development of laboratory accreditation program}

On November 27, 1990, the Lighting Equipment Division of the National Electrical Manufacturers Association (NEMA) requested that the National Voluntary Laboratory Accreditation Program (NVLAP), which is the laboratory accreditation group within the National Institute of Standards and Technology (NIST), establish an accreditation program for laboratories that test certain types of lamps and luminaires. The announcement of the development of the NVLAP Energy Efficient Lighting Products (EEL) Laboratory Accreditation Program (LAP) was published in the Federal Register on May 15, 1991. The purpose of the program is to accredit testing laboratories to assure that standard test methods for product performance (excluding product safety) are followed in testing electric lighting products (10 CFR 430.25).

In 2008 NVLAP updated NIST Handbook 150-1 to include new requirements set forth in EPAct 2005, including the test methods cited in the ENERGY STAR ${ }^{\circledR}$ program. EPAct 2005 formally recognizes the federal ENERGY STAR ${ }^{\circ}$ program (Section 131 of the Energy Policy Act, Public Law 109-58) to identify and promote energy-efficient products and buildings through labeling. As written in Section 131: "There is established within the U.S. Department of Energy and the U.S. Environmental Protection Agency a voluntary program to identify and promote energy-efficient products and buildings in order to reduce energy consumption, improve energy security, and reduce pollution through voluntary labeling of, or other forms of communication about, products and buildings that meet the highest energy conservation standards.” Section 131 calls for enhancing public awareness of ENERGY STAR®, preserving the integrity of the label, regularly updating performance criteria, soliciting comments from interested parties, and providing appropriate lead time when changes are being made to program criteria.

As part of the ENERGY STAR ${ }^{\circledR}$ program for solid state lighting, the Department of Energy requested that NVLAP add to the NVLAP EEL LAP specific test methods used in testing certain types of solid state lighting products and LED sources. The purpose of this addition of test methods is to accredit testing

\footnotetext{
${ }^{1}$ Refer to Code of Federal Regulations, Title 10 - Energy, Part 430 - Energy Conservation Program for Consumer Products (10 CFR Part 430) and Title 42 U.S. Code 6291-6295 for the energy efficiency standards and related test procedures.
} 
laboratories to ensure that standard test methods for product performance (excluding product safety) are followed in testing solid state lighting products and LED sources. NIST Handbook 150-1A initially presented the technical requirements and guidance for the accreditation of laboratories for testing solid state lighting products and LED sources. Those requirements have been incorporated into NIST Handbook 1501 to minimize the number of documents, since many of the requirements are similar. 


\section{General information}

\subsection{Scope of handbook}

1.1.1 NIST Handbook 150-1 specifies the technical requirements and provides guidance for the accreditation of laboratories under the NVLAP Energy Efficient Lighting Products Laboratory Accreditation Program (EEL LAP). It supplements the NVLAP procedures and general requirements found in NIST Handbook 150, NVLAP Procedures and General Requirements and ISO/IEC 17025-2017, by tailoring the general criteria found in NIST Handbook 150 to the specific tests and types of tests covered by the EEL LAP.

1.1.2 NIST Handbook 150, NIST Handbook 150-1 and ISO/IEC 17025-2017, and their respective checklists (see 1.6) constitute the collective body of requirements that must be met by a laboratory seeking NVLAP accreditation to specific test methods for the EEL Program.

1.1.3 This handbook is intended for information and use by accredited EEL laboratories, assessors conducting onsite assessments, laboratories seeking accreditation, other laboratory accreditation systems, users of laboratory services, and others needing information on the requirements for accreditation under the EEL Program.

\subsection{Organization of handbook}

The numbering and titles of clauses six through eight of this handbook match those of ISO/IEC 17025:2017. The primary subclauses in clauses six through eight (e.g., 6.1, 6.2, etc.) are also numbered and titled to correspond with ISO/IEC 17025:2017, even when there are no additional requirements.

\subsection{Program description}

1.3.1 The NVLAP EEL LAP provides for laboratory accreditation to ensure that standard test procedures are followed to measure electrical, photometric, colorimetric, and life-performance characteristics of incandescent, fluorescent, and high intensity discharge lamps; to measure the photometric characteristics of luminaries (lighting fixtures) using the above-named sources; and to measure electrical, photometric, colorimetric, lumen maintenance characteristics and life performance characteristics of solid state lighting products and LED sources.

1.3.2 The EEL LAP accredits laboratories through the use of test methods or procedures developed by the Illuminating Engineering Society (IES), standards entitled “ANSI” (American National Standards Institute), Energy Star, IEC and procedures developed by the Commission Internationale de l'Eclairage (CIE).

1.3.3 A listing of the test methods included in the EEL LAP is available on the NVLAP website. The test methods are grouped into tests for lamps, luminaires (lighting fixtures), and solid state lighting. A laboratory may seek accreditation to all of the methods offered in the EEL LAP or a subset of its choice. A laboratory may request that test methods be added to the program. Test method additions will be handled in accordance with NVLAP procedures in NIST Handbook 150 for adding to or modifying an established laboratory accreditation program (LAP) (see NIST Handbook 150, clause 2). 


\subsection{References}

The following documents are referenced in this handbook. For dated references, only the edition cited applies. If no date is given in the reference, then the latest edition (including any amendments) shall apply within one year of publication or within another time limit specified by regulations or other requirement documents.

- ANSI/IESNA RP-16-17, Nomenclature and Definitions for Illuminating Engineering, Illuminating Engineering Society of North America

- NIST Handbook 150, NVLAP Procedures and General Requirements

_ ISO/IEC 17025 General requirement for the competence of testing and calibration laboratories

\subsection{Terms and definitions}

For the purposes of this handbook, the terms and definitions given in NIST Handbook 150 and ANSI/IESNA RP-16-17 apply. In particular, the following are provided from ANSI/IESNA RP-16-17.

\subsection{1}

lamp

A generic term for a manufactured source created to produce optical radiation. By extension, the term is also used to denote sources that radiate in regions of the spectrum adjacent to the visible.

\subsection{2}

\section{LED lamp, integrated}

An integrated assembly comprised of LED packages (components) or LED arrays (modules), LED driver, ANSI standard base, and other optical, thermal, mechanical, and electrical components. The device is intended to connect directly to the branch circuit through a corresponding ANSI standard lamp-holder (socket).

\subsection{3}

\section{LED luminaire (solid state lighting luminaire)}

A complete lighting unit consisting of LED-based light emitting elements and a matched driver together with parts to distribute light, to position and protect the light emitting elements, and to connect the unit to a branch circuit. The LED-based light emitting elements may take the form of LED packages (components), LED arrays (modules), and LED light engine, or LED lamps. The LED luminaire is intended to connect directly to a branch circuit.

\subsection{4}

\section{luminaire (light fixture)}

A complete lighting unit consisting of a lamp(s) and ballast(s) (when applicable), together with the parts designed to distribute the light, to position and protect the lamps, and to connect the lamps to the power supply. 


\subsection{Program documentation}

\subsubsection{General}

Assessors use NVLAP checklists to ensure that each laboratory receives an assessment comparable to that received by others and to assure completeness, uniformity, and objectivity. Checklists assist assessors in documenting the assessment to the NVLAP requirements found in NIST Handbook 150, this handbook, and the ISO/IEC 17025-2017 checklists themselves. Checklists contain definitive statements or questions about all aspects of the NVLAP requirements for accreditation and form part of the onsite assessment report (see NIST Handbook 150). The current version of each checklist is available from NVLAP.

\subsubsection{NIST Handbook 150 Checklist}

All NVLAP programs use the NIST Handbook 150 Checklist (formerly called the General Operations Checklist), which contains the requirements published in ISO/IEC 17025:2017 and NIST Handbook 150. The checklist items are numbered to correspond to clauses 4 through 8 of ISO/IEC 17025:2017 and annexes A, B, and E of NIST Handbook 150.

\subsubsection{NIST Handbook 150-1 Checklist}

The NIST Handbook 150-1 Checklist (also referred to as the EEL program specific checklist) addresses the requirements specific to energy efficient lighting product testing given in NIST Handbook 150-1 (this handbook) with an emphasis on observing test performance, testing accuracy and uncertainty, traceability and associated calibration uncertainty of standard reference lamps and standard photometers, instrumentation, calibration, personnel competency, and test reporting.

\subsubsection{Test Method Review Summary}

The assessor uses the Test Method Review Summary to review the laboratory's ability to perform EEL test methods. The review of test methods by the assessor ranges from observing tests to having laboratory staff describe the test procedures. The assessor notes on the Test Method Review Summary the depth into which each part of the test method was reviewed (observed test, walked/talked through test, listened to description of procedures, examined apparatus).

\subsubsection{NVLAP lab bulletins}

NVLAP lab bulletins are issued to laboratories and assessors, when needed, to clarify program-specific requirements and to provide information about program additions and changes. NVLAP lab bulletins dealing with the EEL LAP are available on the NVLAP website, <https://www.nist.gov/nvlap>.

\section{LAP establishment, development and implementation}

This clause contains no information additional to that provided in NIST Handbook 150, clause 2. 


\section{$3 \quad$ Accreditation process}

\subsection{General}

An overview of the laboratory accreditation process is provided in NIST Handbook 150, clause 3, and includes information pertaining to application for accreditation, onsite assessment, proficiency testing, or similar programs, accreditation decision, granting accreditation, renewal of accreditation, changes to scope of accreditation, monitoring visits, and suspension, denial, revocation, and voluntary termination of accreditation.

\subsection{Management system review}

3.2.1 Prior to applying to NVLAP for accreditation, a laboratory shall have a fully implemented management system.

3.2.2 Prior to the onsite assessment, the assigned assessor reviews all relevant management system documentation for conformity with NVLAP requirements, including the requirements of this handbook, NIST Handbook 150, and ISO/IEC 17025. During this review, the assessor may request additional management system and/or technical documents and/or records, which will be returned upon request.

\subsection{Onsite assessment}

3.3.1 The purpose of the onsite assessment is to determine whether the laboratory is following its documented management system and to assess the competence of the laboratory's delivery of its testing services.

3.3.2 The onsite assessment will take place at the laboratory site. Prior to the visit, the NVLAP assessor provides a preliminary agenda, which may change due to findings observed during the onsite assessment. Efforts will be made to minimize disruption to the normal working routines during the assessment. The assessor will need time and workspace to complete assessment documentation during his/her time at the laboratory site.

3.3.3 All laboratory equipment required to perform accredited testing shall be available for assessment and in good working order. Although all test methods on the scope or proposed scope of accreditation need not be set up during the onsite assessment, the laboratory shall be prepared to demonstrate selected test methods as requested by the assessor. For those cases where a demonstration is not requested, the laboratory shall be prepared to describe the test method and procedures it would follow and show the actual equipment, fixtures, and arrangements that would be used. The assessment will cover the requirements identified in this handbook, NIST Handbook 150, ISO/IEC 17025, the laboratory's management system documentation, and the laboratory's written detailed test instructions.

3.3.4 The laboratory shall make available all supporting technical information in a format that is conducive to a detailed review. The assessor may request additional information to clarify issues regarding nonconformities or to delve more deeply into technical issues.

3.3.5 The activities covered during a typical onsite assessment are described below. 
a) Opening meeting: The NVLAP assessor will meet with laboratory management, supervisory personnel, and other appropriate staff members as determined by the laboratory to explain the purpose of the onsite assessment and to discuss the schedule for assessment activities. Information provided by the laboratory on its application form may be discussed during this meeting.

b) Staff interviews: The assessor will ask the laboratory manager to assist in arranging times for individual interviews with laboratory staff members. The assessor will interview staff members filling key positions (e.g., laboratory manager, technical manager, quality manager, authorized representative, approved signatories) and staff members who have an effect on the outcome of testing, including staff who conduct testing. The assessor does not need to talk to all staff members; however, the assessor will select staff members representing all aspects of the laboratory. These interviews are conducted to determine if the staff members are properly trained, assigned, and supervised, and are technically competent for the tasks assigned to them.

c) Records review: The assessor will review laboratory documentation, including the management system documentation, equipment and maintenance records, record-keeping procedures, testing procedures, laboratory test records and reports, personnel competency records, personnel training plans and records, and safeguards for the protection of sensitive and proprietary information. The assessor will review the laboratory's own detailed instructions, if applicable, to perform EEL testing according to the standard test procedures for which the laboratory is accredited (or is seeking accreditation), the range of energy efficient lighting products and conditions it can test, and the descriptions of the maintenance and calibration of its specific equipment. The assessor will also review:

1) sample identification and tracking procedures and copies of completed test reports;

2) records of internal audits, use of quality control procedures, and participation in NVLAP proficiency testing or other similar programs;

3) personnel records, including résumés and job descriptions of key personnel, and competency evaluations for all staff members who routinely perform the test method for which accreditation is sought;

4) calibration records and certificates (see 6.4.5);

5) records of evaluations, verifications, and testing of purchased services, equipment, etc.

Laboratory staff shall be available to answer questions pertaining to the accreditation review; however, the assessor may wish to review documents and records alone. The assessor usually does not ask to remove any laboratory documents or records from the laboratory premises.

d) Internal audit and management review: The assessor will review and discuss with the laboratory staff the laboratory's internal audit and management review activities, which are separate and distinct activities. The discussion will include all aspects of those activities including management system procedures, audit findings, cause determination, actions taken to resolve problems identified, actions taken to prevent recurrence, and results of the management review.

e) Equipment and software: The assessor will examine and determine the suitability of all equipment and facilities required to perform the standard test methods for which the laboratory is accredited (or is seeking accreditation). The appropriate environmental conditions required for testing will be assessed. The assessor will observe the demonstration of selected procedures by appropriate 
personnel assigned to conduct the tests and will interview those personnel. The assessor will review test data, examine hardware and software for function and appropriateness, and review software validation and verification procedures and records.

f) Demonstrations: Demonstrations requested may be selective or all-inclusive. The assessor will observe demonstrations of testing procedures by technical personnel assigned to conduct testing, and will discuss testing with technical personnel to assure their understanding of procedures. Demonstrations shall include sample energy efficient lighting product(s), preparation of devices, establishment of test conditions, and setup/use of major equipment. The assessor will use the Test Method Review Summary (see 1.6.4) and the EEL program-specific checklist (see 1.6.3) in reviewing and summarizing the laboratory's ability to conduct the test methods.

The assessor may select and trace the history of one or more energy efficient lighting product samples from receipt to final issuance of the test reports.

g) Quality control: The assessor will discuss all aspects of quality control results (see section 7.7 of ISO/IEC 17025:2017, Ensuring the validity of results) with appropriate staff. Test methodology and records documenting the laboratory's execution of testing will be reviewed and discussed. Any unusual trends or outlying results will be discussed.

The assessor may provide an energy efficient lighting product(s) as a test specimen and request testing or demonstration.

h) Onsite assessment report: The assessor will complete an onsite assessment report, which summarizes findings and clearly lists all nonconformities and comments (positive or negative). This report normally consists of the Onsite Assessment Narrative Summary, the NVLAP General Criteria Checklist (ISO/IEC 17025-2017, the EEL 150-1 Checklist, and the Test Method Review Summary. The first page of the report shall be signed by the assessor and the laboratory's authorized representative or designee to acknowledge receipt of the onsite report, but signing the report does not necessarily indicate agreement by the laboratory. A copy of the report will be given to the laboratory representative for retention and the assessor will upload all reports, comments and nonconformities to the NIWS portal. All observations made by the assessor will be held in confidence as stated in the declaration signed by all assessors and NVLAP staff.

i) Closing meeting: The assessor will conduct a closing meeting with the laboratory manager, supervisory personnel, and other appropriate staff members to discuss the findings. During the visit the assessor will have identified all nonconformities and comments. These will be discussed at the closing meeting and resolutions may be mutually agreed upon. The assessor will specifically note items that have been corrected during the onsite assessment along with any recommendations for other action(s). The process for resolving nonconformities identified during the onsite assessment is documented in NIST Handbook 150. Disagreements between the laboratory and the assessor shall be referred to NVLAP for resolution.

3.3.6 The laboratory shall review all comments for potential improvements in energy efficient lighting product testing.

\subsection{Proficiency testing}

3.4.1 NIST Handbook 150 defines proficiency testing and describes how it is included in the accreditation process. Special proficiency testing rounds may be scheduled separately for specific needs. 
Proficiency testing fees are required from all laboratories accredited for one or more test methods for which proficiency testing is being offered.

3.4.2 Laboratories applying for initial accreditation for solid state test methods shall participate satisfactorily in bilateral proficiency testing with NIST before accreditation is granted. Solid state lighting products and LED sources along with instructions for specimen handling, preparation (including seasoning and pre-burning), conditioning, mounting, and testing, and data forms are provided to the participating laboratory. The completed test data forms are sent by the participating laboratories to NIST. The results are summarized in a report, which is provided to the laboratory and NVLAP.

3.4.3 Laboratories applying for initial accreditation for test methods that do not include solid state test methods are not required to participate in proficiency testing before accreditation is granted.

3.4.4 Laboratories renewing accreditation shall have satisfactorily participated in all required proficiency testing during their previous accreditation period. Failure to participate in proficiency testing or to return the completed test data forms by the deadline is considered a nonconformity and may result in suspension of laboratory accreditation for those test methods in question.

3.4.5 The proficiency testing shall not be contracted to another laboratory.

3.4.6 In no case shall proficiency test samples be considered as calibration standards or standard reference materials or be used as substitutes for calibration standards that are traceable to NIST or other national metrology institutes (NMIs).

3.4.7 All proficiency test samples, like all other samples received by the laboratory, shall be listed or entered into the normal sample tracking and identification system for control and data recording.

3.4.8 Using the test data from proficiency testing, the laboratory shall monitor its own testing performance. Procedures for analyzing and monitoring the laboratory's own test results shall be documented in its management system.

3.4.9 Unsatisfactory performance in proficiency testing (e.g., outlying results) is a technical nonconformity that shall be resolved by the laboratory through its corrective action process to maintain its accreditation for the test method(s) in question. If the laboratory performs unsatisfactorily in any proficiency test, it shall take corrective action to investigate and resolve nonconformities in a timely manner, according to the requirements in 7.10 of ISO/IEC 17025:2017 for the control of nonconforming work. Unsatisfactory performance in proficiency testing may result in suspension or revocation of accreditation.

3.4.10 The results of proficiency testing shall be made available to NVLAP assessors for review during onsite assessment visits. Any problems indicated by proficiency testing shall be discussed with appropriate laboratory personnel responsible for developing and implementing plans for resolving the problems.

\section{General requirements}

There are no requirements additional to those set forth in ISO/IEC 17025:2017.

\section{Structural requirements}

There are no requirements additional to those set forth in ISO/IEC 17025:2017. 


\section{Resource requirements}

\subsection{General}

There are no requirements additional to those set forth in ISO/IEC 17025:2017.

\subsection{Personnel}

\subsubsection{Personnel records}

6.2.1.1 Key NVLAP accreditation personnel - The laboratory shall maintain a record of personnel designated to fulfill NVLAP requirements including: laboratory manager, technical manager, NVLAP authorized representative, NVLAP approved signatories, and staff responsible for conducting testing. This document shall be reviewed by the assessor at the onsite assessment.

6.2.1.2 All testing laboratory staff — The laboratory shall document and maintain records of each staff member, including a résumé of qualifications, laboratory testing procedures to which the person is assigned and authorized to perform, and the results of periodic testing performance (competency) reviews (see also 6.2.3.4).

6.2.1.3 Notification of changes - The laboratory shall notify NVLAP within 30 days of a change in the NVLAP authorized representative or approved signatories.

\subsubsection{Specific experience and competence of technical manager}

The laboratory's technical manager shall have a combination of knowledge, experience, and training in testing energy efficient lighting products defined on the (proposed) scope of accreditation and shall have technical competence and supervisory capability to direct the work of professionals and technicians in testing energy efficient lighting products.

\subsubsection{Competency reviews}

6.2.3.1 The laboratory shall develop an appropriate list of staff member competencies for each test method. Competencies may include specimen preparation and/or mounting techniques; techniques for measuring ambient thermal conditions; lamp seasoning and stabilization procedures; procedures for transporting lamps between warm-up racks and measurement apparatus; voltage, current, and electrical power measurements; oscilloscope measurements; ballast circuit connection and verification; photometric calibration techniques; thermocouple mounting and calibration; colorimetric measurement techniques; and goniophotometric measurement techniques, among many possible competencies .

6.2.3.2 The laboratory shall evaluate the competency of each staff member for each test method or part of a test method the staff member is authorized to conduct.

6.2.3.3 For each staff member, the staff member's immediate supervisor or designee shall conduct annually an assessment of performance competence.

6.2.3.4 These annual performance competency reviews shall be documented, dated, signed by the supervisor and employee, retained in the personnel files, and be available for review by the assessor. For the purpose of onsite assessments, a separate personnel folder of information specific to applicable NVLAP 
requirements may be provided instead of the complete folder, which may contain confidential information not needed for the assessment.

\subsubsection{Training}

A training program shall be maintained and documented. Authorized staff members shall be given additional training when accredited test methods are updated or procedures changed, or when the individuals are assigned new responsibilities.

NOTE Each staff member may receive training for assigned duties either through on-the-job training, formal classroom study, attendance at conferences, or other appropriate mechanisms.

\subsection{Facilities and environmental conditions}

There are no requirements additional to those set forth in ISO/IEC 17025:2017.

\subsection{Equipment}

6.4.1 Proper performance and calibration of measurement, test equipment and reference standard lamps shall be periodically verified as needed through the use of cross-checks and/or working standards. The periodical verification shall be recorded.

6.4.2 The laboratory shall maintain a record of usage, in hours, of standard (or reference) lamps.

6.4.3 Standard (or reference) lamps shall be recalibrated at appropriate intervals determined by the laboratory.

NOTE Typical reference lamps decrease in luminous intensity by $0.6 \%$ every 24 hours of burning time when operated at a current that produces a correlated color temperature of $2856 \mathrm{~K}$. An acceptable calibration interval for a standard reference lamp would be 30 hours to 50 hours of burning time.

6.4.4 The reference standards used and the environmental conditions at the time of calibration shall be recorded for all calibrations.

6.4.5 The following requirements apply for calibrations and calibration certificates.

a) Certificates shall be required for calibrations performed by outside services. A calibration certificate shall indicate measurement uncertainty or accuracy tolerance limits.

b) Records shall be required when a laboratory performs its own calibration including the identity of the properly trained personnel involved, the standard metrological procedures used, the environmental conditions, and the measurement uncertainty. Evidence and demonstration of traceability as required in NIST Handbook 150, Annex B, shall be documented. Records shall contain sufficient information to permit repetition of the calibration (see appendix A).

c) Laboratories using standard (or reference) lamps and/or standard photometers shall document the traceability chain and, for each step, the magnitude of the associated measurement uncertainty.

6.4.6 The laboratory shall conduct a test after every calibration to assure and validate that the calibration of the system is acceptable. 
NOTE One way to verify calibration is to measure a check lamp. Measured values of the check lamp should be within predefined limits, e.g., +/- $1 \%$ for lumen output.

6.4.7 The laboratory shall have a documented method, including frequency or schedule, to assure that the check lamps used to verify calibration results are valid; i.e., the measured values have not changed but are within a given limit of repeatability.

NOTE One way to assure the required reproducibility of the check lamp is to use three lamps to check calibration results. Measured values of all three lamps shall be within a predetermined limit of their previous values.

\subsection{Metrological traceability}

Measurement traceability is a property of the measurement result. Traceability is established to the stated reference usually through the calibration of the measurement and test equipment used to conduct the test. Calibration is achieved with the use of a reference standard having a known value(s) and uncertainty and with established traceability to a national metrology institute. The laboratory shall determine equipment calibration intervals based on the equipment's frequency of use, the environment in which it is used, and in accordance with standard test methods and/or manufacturer's recommendations.

\subsection{Externally provided products and services}

There are no requirements additional to those set forth in ISO/IEC 17025:2017.

\section{$7 \quad$ Process requirements}

\subsection{Review of requests, tenders and contracts}

There are no requirements additional to those set forth in ISO/IEC 17025:2017.

\subsection{Selection, verification and validation of methods}

7.2.1 The laboratory shall have readily available, in either electronic or paper format, all technical standards for which accreditation is being requested.

7.2.2 When a technical standard contains normative references, the laboratory shall have the referenced documents readily available where necessary for proper implementation of the standard.

7.2.3 The management system documentation shall contain or reference detailed written documentation of the procedures, practices, instructions, and equipment that the laboratory uses in conducting the test methods for the different types of lamps, luminaires, solid state lighting products or LED devices for which it seeks or holds accreditation. These detailed instructions, including those for equipment operation, calibration checks, quality control checks, and operation of particular type(s) of devices tested shall address any laboratory-specific information not contained in the standard method and shall be supplemented with additional detailed instructions beyond the test method to ensure consistent application. Simply referencing the IES LM or ANSI standard is not acceptable.

7.2.4 Self-absorption correction procedures shall be applied for sphere measurements, or documented evidence shall be collected demonstrating that self-absorption correction is not required. 


\subsection{Sampling}

All requirements of ISO/IEC 17025:2017 for sampling apply to subsampling. When a laboratory tests some subset of the test items supplied by the customer, it is subsampling.

\subsection{Handling of test or calibration items}

There are no requirements additional to those set forth in ISO/IEC 17025:2017.

\subsection{Technical records}

There are no requirements additional to those set forth in ISO/IEC 17025:2017.

\subsection{Evaluation of measurement uncertainty}

The management system documentation shall list the important components that substantially affect the measurement uncertainty of the test results for each test method on the (proposed) scope of accreditation. This can be done for groups of similar test methods (e.g., grouped by electrical, photometric [intensity, flux], life-performance properties, or lumen maintenance, in situ temperature, start time) rather than for each test method. Further, an estimate of the magnitude of identified uncertainty contributions shall be provided. The uncertainty shall be calculated and reported if required by the test method, the regulator, or the customer.

NOTE The uncertainty contribution of the important components only need be approximated. At this time, documentation validating the uncertainty contribution is not required.

\subsection{Ensuring the validity of results}

Procedures for the laboratory's participation in proficiency testing, including analyzing and monitoring the laboratory's results, a description of any corrective actions taken because of the results, and procedures for comparing the laboratory's proficiency test results with those from NIST or other NVLAP-accredited laboratories shall be documented.

\subsection{Reporting of results}

7.8.1 Test reports shall clearly reference the test method and edition, including the published year, used for testing.

7.8.2 The laboratory personnel responsible for report writing and generation shall be available to be interviewed by the assessor during the laboratory's onsite assessment.

\subsection{Complaints}

There are no requirements additional to those set forth in ISO/IEC 17025:2017.

\subsection{Nonconforming work}

There are no requirements additional to those set forth in ISO/IEC 17025:2017. 


\subsection{Control of data and information management}

There are no requirements additional to those set forth in ISO/IEC 17025:2017.

\section{$8 \quad$ Management system requirements}

\subsection{Options}

There are no requirements additional to those set forth in ISO/IEC 17025:2017.

\subsection{Management system documentation}

The laboratory shall create a cross-reference document that facilitates verification by both the laboratory and the NVLAP assessor that all program requirements have been addressed by the management system if the management system does not follow the outline of ISO/IEC 17025:2017. This review includes clauses 4 through 8 of ISO/IEC 17025:2017 and annexes A, B, and E of NIST Handbook 150 and NIST Handbook 150-1.

\subsection{Control of management system documents}

There are no requirements additional to those set forth in ISO/IEC 17025:2017.

\subsection{Control of records}

Records shall be kept for a period of at least three years unless a longer period is required by the customer, regulation, or the laboratory's own procedures.

\subsection{Actions to address risks and opportunities}

There are no requirements additional to those set forth in ISO/IEC 17025:2017.

\subsection{Improvement}

There are no requirements additional to those set forth in ISO/IEC 17025:2017.

\subsection{Corrective actions}

There are no requirements additional to those set forth in ISO/IEC 17025:2017.

\subsection{Internal audits}

8.8.1 The internal audit shall cover compliance with NVLAP, laboratory management system, contractual, testing, and test method requirements, and shall be completed at an interval no greater than two years. A NVLAP onsite assessment does not take the place of an internal audit.

8.8.2 An applicant laboratory shall conduct at least one complete internal audit, including the test methods on the laboratory's proposed scope of accreditation, prior to the first onsite assessment. The internal audit report and pertinent records will be reviewed by the NVLAP assessor during the onsite assessment. 


\subsection{Management reviews}

8.9.1 Periodic reviews of the management system shall reflect adherence to NVLAP requirements and the laboratory's quality objectives and shall be completed, at a minimum, on an annual basis.

8.9.2 An applicant laboratory shall perform at least one complete management review prior to the first onsite assessment. The management review report(s) and pertinent records will be reviewed by the NVLAP assessor before or during the onsite assessment.

8.9.3 For accredited laboratories, reports and pertinent records for management reviews conducted since the previous onsite assessment shall be made available for review during the onsite assessment. 


\section{Appendix A}

\section{(non-normative)}

\section{In-house Calibration Matrix}

The following table represents equipment commonly calibrated in-house by laboratories and the information commonly reviewed by assessors for these calibrations.

\begin{tabular}{|c|c|c|c|c|c|c|}
\hline & Equipment Description & $\begin{array}{c}\text { Luminous Flux } \\
\text { Standards }\end{array}$ & $\begin{array}{l}\text { Spectral Flux } \\
\text { Standard }\end{array}$ & $\begin{array}{l}\text { Luminous } \\
\text { Intensity } \\
\text { Standards }\end{array}$ & $\begin{array}{c}\text { Integrating } \\
\text { Spheres }\end{array}$ & $\begin{array}{c}\text { Gonio- } \\
\text { photometers }\end{array}$ \\
\hline & Calibration Record & & & & & \\
\hline \multirow{6}{*}{ 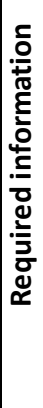 } & Personnel & & & & & \\
\hline & Procedure & & & & & \\
\hline & Environment & & & & & \\
\hline & Traceability & & & & & \\
\hline & Uncertainty Statement & & & & & \\
\hline & Uncertainty Analysis & & & & & \\
\hline
\end{tabular}

